\title{
Erratum to: Are there differences on tooth movement between different sectional canine retractors?
}

\section{Erratum zu: Haben verschiedene Eckzahnretraktoren in Teilbogentech- nik unterschiedliche Auswirkungen auf die Zahnbewegung?}

Journal of Orofacial Orthopedics/Fortschritte der Kieferorthopädie 74:226-23 http://dx.doi.org/10.1007/s0056-013-0142-3

Belma Işik Aslan', Burcu Baloş Tuncer, Müfide Dinçer ${ }^{1}$

Please note the following corrected versions of Figure 1 and Figure 2.

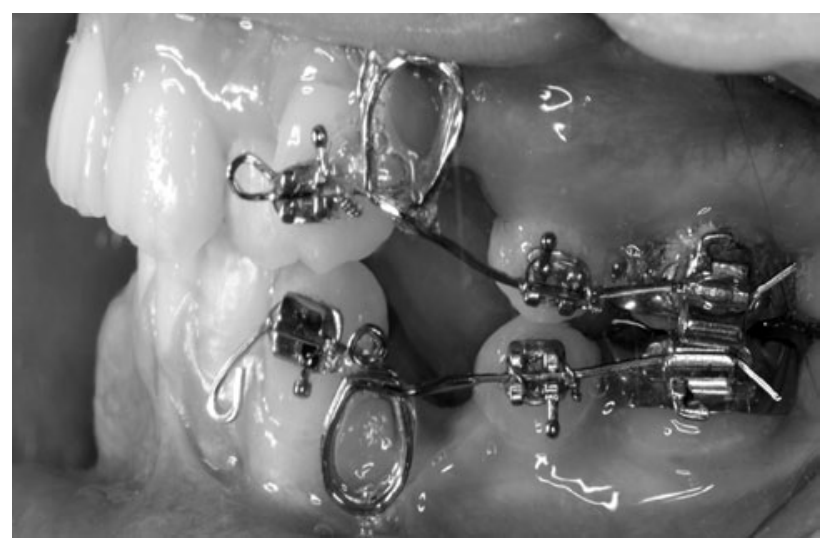

Figure 1. $P G$ retractor

Abbildung 1. PG-Retraktor
Wir bitten um Beachtung der hier dargestellten korrigierten Versionen der Abbildung 1 und der Abbildung 2.

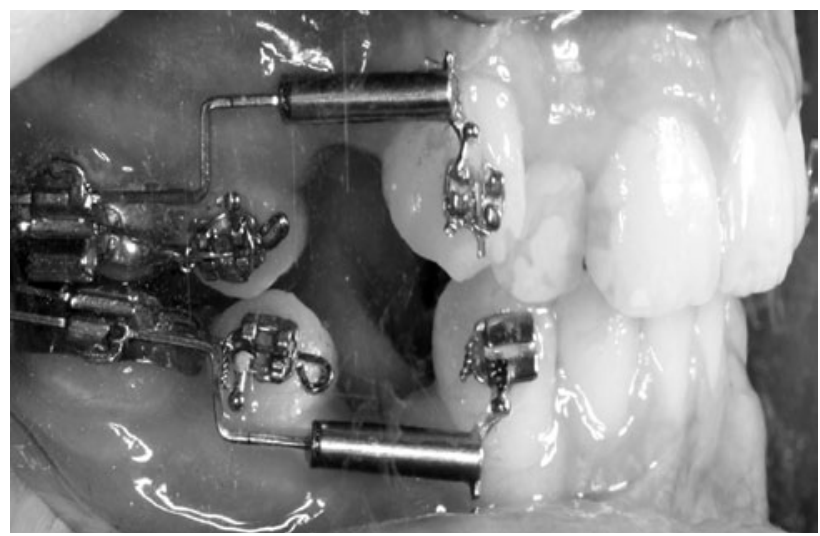

Figure 2. Hybrid retractor.

Abbildung 2. Hybrid-Retraktor

\section{Correspondence address}

Dr. Belma Işik Aslan

Department of Orthodontics

Faculty of Dentistry

Gazi University

06510 Emek, Ankara

Turkey

belmaslan2003@yahoo.com

J Orofac Orthop 2013; 74:435

DOI 10.1007/s00056-013-0160-1 